\title{
Coming in '96: IPEDS adds new data items
}

New data items will be included in the IPEDS Academic Libraries survey form (ALS) that will be mailed in July 1996. IPEDS-the Integrated Postsecondary Education Data System-is a set of nine questionnaires distributed periodically by the National Center for Education Statistics (NCES). Most are annual but the Academic Libraries survey is one of three sent biennially.

For many years the ALS had five parts (A-F): Outlets, Staff, Expenditures, Collections, Services Per Fiscal Year (e.g., circulation), and Services Per Typical Week (e.g., reference). A new Part G, Electronic Services, will be added in '96. Unlike other parts of the form, Part $\mathrm{G}$ asks the respondent to give only a Yes/ No answer to whether or not the institution offers 13 different electronic services. The new Part $G$ will probably not be in a permanent part of the ALS. Instead it will gather data to describe where libraries are now in a rapidly changing aspect of their services.

Additions were also made to Part E which includes: Document Delivery/Interlibrary Loan. Previous surveys asked only for the number of items provided to other libraries and received from other libraries. The new form asks for a breakclown of each total into "returnables" and "non-returnables." The new items were added in recognition of the fact that interlibrary loan is not what it once was-loans between libraries. Today agencies other than libraries are often involved and many irems are sold or given away, not loaned. The current change recognizes that and will enable TPEDS to document what is happening.

Several other changes were made, not to add items, but to update or clarify intent. The

and appointed members in chapters, sections, committees, and discussion groups. She will also plan, develop, and manage ACRL's preconferences and Annual Conference programs. In addition, Topper will provide advisory services on issues of interest to academic librarianship and function as a member of the ACRL staff managerial team.

Topper had been with the Jewish Vocational Service, an affiliate of the Jewish Federation in Chicago, since 1983, most recently as director instructions on Expenditures and Collections were modified to take into account electronic journals and automated catalogs. The instructions for gate count and reference transactions were modified to clarify that respondents should report figures for a "typical week."

The 1992 ALS report does not include figures for those variables because NCES noticed several problems in the data just before publication. In order to plan for the future, the ALA Office for Research and Statistics worked with a contractor and an Advisory Committee of academic libraries to analyze the 1992 data in search of a formula that could be applied to 1994 data at an early point in survey processing. That formula discovered 515 libraries whose 1994 data for one or both of the two variables was suspect. Those libraries were contacted and data were either corrected (most cases) or confirmed (a few cases). The process of correcting or confirming those figures was labor-intensive and cannot be repeated. It is hoped that changes on the form will alert people to what is wanted.

Additional detail on these changes, including a copy of the new Part $G$, definition of returnables and nonreturnables, and names of Advisory Committee members, may be found on the ALA gopher. Point your gopher to University of Illinois at Chicago in the menu of all servers maintained on gopher at the University of Minnesota. Alternatively, you can connect your favorite gopher client directly to host "gopher.uic.edu:70", select The Library, ALA, XV. Offices, then Office for Research and Statistics, then "Coming in '96: IPEDS Adds New Data Items."-Mary Jo Lynch, ALA Office for Research and Statistics

of information services. She managed the library and the Information Services Department at the nonprofit agency, counselling and providing professional development to individuals at all career stages. Prior to that Topper was director of training and the career librarian at the Chicago Public Library. She received her MLS from Florida State University and a master's of industrial relations/career development from Loyola University in Chicago. She is a member and former Career Development Chair of the 